\title{
Türkiye'de Enflasyon Hedeflemesi Politikasının Başarısı ve GDP Hedeflemesi Politikası
}

İsmail Cem ÖZKURT (https://orcid.org/0000-0003-0871-9215), Department of Economics, Kafkas University, Turkey; e-mail: icozkurt@gmail.com

\section{An Assessment of the Inflation Targeting Policy in Turkey and Evaluation of the GDP Targeting Policy as an Alternative}

\begin{abstract}
The inflation targeting policy is a monetary policy that was first implemented in New Zealand in the 1990s and then implemented in developed and developing countries worldwide. Inflation targeting policy, which had found wide application until the 2008 global financial crisis, caused the emergence of specific problems, especially in developing countries. As the inflation targeting policy was ineffective in solving these problems, the applicability of the GDP (Gross Domestic Product) targeting policy, which was previously argued for in the literature, has started to be discussed again. This study assesses the success of the inflation targeting policy in Turkey and provides a general understanding of the GDP targeting policy as an alternative.

Keywords : Inflation, Monetary Policy, Gross Domestic Product, Central Bank.

JEL Classification Codes : E31, E52, E58, E64.

Öz

Enflasyon hedeflemesi politikası 1990'lı yıllardan itibaren ilk olarak Yeni Zelanda'da uygulanmaya başlanan daha sonra tüm Dünya'da hem gelişmiş hem de gelişmekte olan ülkelerde uygulanan bir para politikasıdır. Özellikle 2008 küresel finansal krizine kadar kendisine geniş bir uygulama alanı bulmuş olan enflasyon hedeflemesi politikası kriz ile birlikte özellikle gelişmekte olan ülkelerde bazı sorunların ortaya çıkmasına yol açmıştır. Sorunların çözümünde enflasyon hedeflemesi politikasının etkisiz kalması üzerine daha önceden de literatürde kendisine yer bulmuş olan GDP (Gross Domestic Product) hedeflemesi politikasının uygulanabilirliği tartışılmaya başlanmıştır. Bu çalışmanın amacı; Türkiye'de uygulanan enflasyon hedeflemesi politikasının başarılı olup olmadığını tespit ederek GDP hedeflemesi politikası hakkında bilgi vermektir.
\end{abstract}

Anahtar Sözcükler $\quad$ : Enflasyon, Para Politikası, Gayri Safi Milli Hasıla, Merkez Bankası. 
Özkurt, İ.C. (2021), “Türkiye'de Enflasyon Hedeflemesi Politikasının

Başarısı ve GDP Hedeflemesi Politikası”, Sosyoekonomi, 29(49), 389-407.

\section{Giriş}

Sayısal bir hedeflemeye dayanan enflasyon hedeflemesi politikası, fiyat istikrarının sağlanmasıyla birlikte, finansal istikrarın da sağlanacağı öngörüsünde bulunurken, yaşanılan 2008 küresel krizinin fiyatların oldukça makul bir seviyede olduğu ve tüm Dünya üzerinde enflasyonun dizginlendiği bir ortamda meydana gelmesi, gözlerin tekrar merkez bankalarına çevrilmesine neden olmuştur. Enflasyon hedeflemesi stratejisinin fiyat istikrarına çok fazla önem atfettiği ve bu nedenle finansal istikrarı sağlayamadığı, bunun yanı sıra ekonomik büyüme ve istihdam hedeflerini ikincil amaç olarak gördüğü noktasında eleştiriler yüksek bir tonda seslendirilmeye başlanmıştır.

Bu eleştiriler sonucunda alternatif bir para politikası arayışları hızlanmıştır. Esasında yeni bir politika olmayan Gayri Safi Milli Hâsıla (Gross Domestic Product, GDP) hedeflemesi stratejisi bu bağlamda tekrar iktisat yazınında kendisine yer bulmaya başlamıştır. Düşük büyüme ve yüksek işsizlik oranlarının varlığı karşısında ekonomilerin likidite tuzağına düştüğü dolayısıyla da genişleme trendinin yakalanamadığı bir ortamda enflasyon hedeflemesi stratejisinin sorunların çözümüne çare olamaması nedeniyle nominal GDP hedeflemesi alternatif bir para politikası olmuştur (Üzar \& Başoğlu, 2017: 125).

Küresel kriz ile birlikte gelişmiş ülkelerde büyüme ve istihdamın canlandırılamaması üzerine nominal GDP hedeflemesi politikasını savunanlar daha yüksek bir GDP'nin hedeflenmesini ve böylece merkez bankasının da buna uyum sağlayarak daha genişletici bir para politikası izlemesi gerektiğini savunmaya başlamışlardır. Genişletici para politikası sayesinde fiyatlar genel seviyesi yükselirken reel faiz oranı düşecek, faiz oranlarının düşmesi kredi piyasasının işlerliğini artırarak tüketim ve yatırım harcamalarının artmasını ve dolayısıyla büyüme ve istihdamın da artmasını sağlayacaktır. Böylelikle gelişmiş ülkeler içine düştükleri resesyonist durumdan kurtulabilecektir. Gelişmekte olan ülkelerde ise öncelikli sorunun ne olduğu konusunun tespit edilmesi önemlidir. Bu gruptaki ülkelerde enflasyondan ziyade; kalkınma, ekonomik istikrar, kurumsallaşma ve gerekli teknolojik altyapının oluşturularak katma değeri yüksek üretimin sağlanması gibi daha yapısal sorunlar ortaya çıkmaktadır. Enflasyonu düşürücü politikalar izlemek aynı zamanda bu sorunları çözmeyi geciktirici bazı olumsuz etkilerde de bulunabilecektir. Tek sorunun enflasyon olmadığı daha önemli yapısal sorunların var olduğu gelişmekte olan ülkeler için evrensel olduğu kabul edilen enflasyon hedeflemesi politikası tek başına yeterli olamamaktadır (Üzar \& Başoğlu, 2017: 142). Bir ülkede var olan yapısal sorunların çözümüne yönelik olarak yapılacak düzenlemeler hedefleme politikasının başarısına da olumlu katkılarda bulunacaktır. Ancak hedeflemedeki başarısızlığın nedeni yapısal sorunlardan değil doğrudan hedefleme politikasından kaynaklanan sorunlardan kaynaklanıyorsa bu durum gelişmekte olan ülkelerin izlediği politikada bir revizyona gitmesi gerektiğinin göstergesidir.

Çalışma dört bölümden oluşmaktadır. Çalışmanın ikinci bölümünde Türkiye'de enflasyon hedeflemesi politikasının genel bir değerlendirmesine yer verilecektir. Bu bölümde Tüketici Fiyatları Endeksi (TÜFE)'ni etkileyen etmenler ve bu etmenlerin 20062020 analiz dönemi boyunca TÜFE'ye olan etkileri göz önüne konulmaya çalışılacaktır. 
Üçüncü bölümde GDP hedeflemesi politikasını açıklayıcı bilgilere yer verilerek GDP hedeflemesi politikasının uygulanma esasları, enflasyon hedeflemesi politikasına göre üstün ve eksik yönlerine yer verilecektir. Dördüncü ve son bölüm ise sonuç ve değerlendirme bölümünden oluşmaktadır.

\section{Türkiye'de Enflasyon Hedeflemesi Politikasının Değerlendirmesi}

Türkiye'de 2002-2005 döneminde uygulanan örtük enflasyon hedeflemesi politikasında gerçekleşmeler hedeflerin altında kalmış elde edilen bu başarı üzerine ve politikanın uygulanabilmesi için gerekli düzenlemelerin tamamlanmasıyla 2006 yılından itibaren tam enflasyon hedeflemesi politikasına geçilmiştir. 2006 yılından itibaren uygulanmaya başlanan tam enflasyon hedeflemesi politikasının değerlendirilmesi bu bölümün konusunu oluşturmaktadır.

Enflasyon hedeflemesi politikasında gösterge olarak TÜFE gibi kapsamlı bir göstergenin kullanılması enflasyon oranlarındaki sapmayı açıklayıcı niteliktedir. TÜFE kapsamında özelikle gıda kaleminin büyük ağırlığa sahip olması ve işlenmiş ve işlenmemiş gıda ürünleri fiyatlarında meydana gelen öngörülemeyen artışların yanı sıra, petrol fiyatlarındaki değişmeler, uluslararası likidite koşullarındaki değişimler, risk algısında meydana gelen bozulmalar, vergi ve fiyatı yönetilen/yönlendirilen ürünlerde yapılan fiyat artışları TÜFE'nin hedeften sapmasına neden olan etmenlerdir. Gelişmekte olan ülkelerde bu etmenlerin daha da güçlü olduğu görülmektedir. Dolayısıyla gelişmekte olan ülkeler hedef bant aralıklarını geniş tutarak hedeften muhtemel sapmaların olumsuz etkilerini gidermeye çalışmışardır (Kara \& Orak, 2008: 49).

\section{Grafik: 1}

\section{TÜFE Hedef ve Gerçekleşmeleri (2006-2020)}

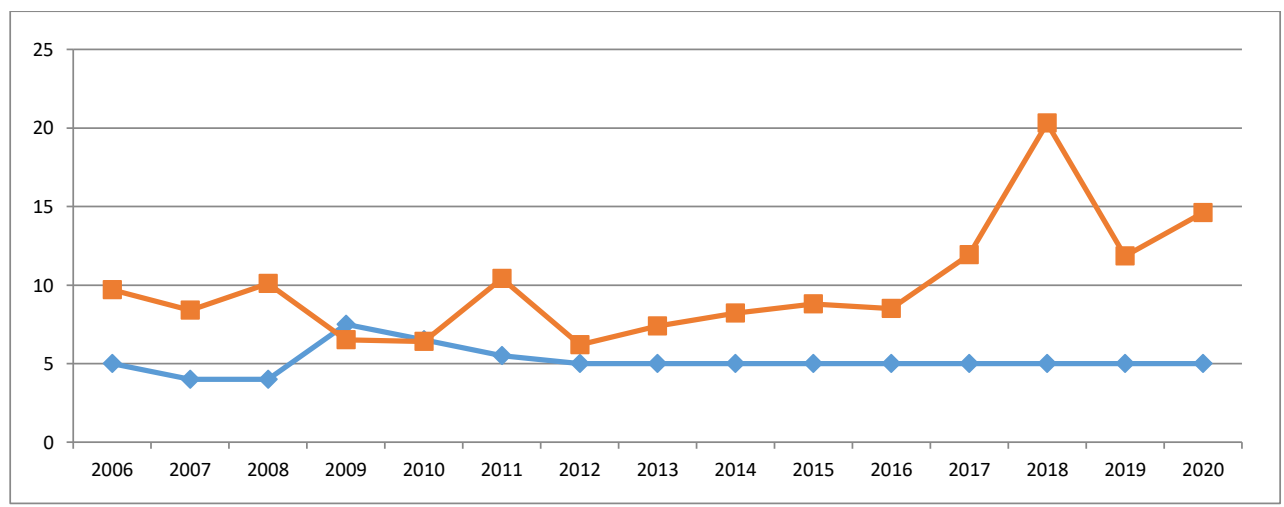

Kaynak:

<https://www.tcmb.gov.tr/wps/wcm/connect/TR/TCMB+TR/Main+Menu/Temel+Faaliyetler/Para +Politikasi/Fiy at + Istikrari+ve+Enflasyon/Enflasyonun + Hedefleri $>$, 05.01.2021. 
Özkurt, İ.C. (2021), “Türkiye'de Enflasyon Hedeflemesi Politikasının

Başarısı ve GDP Hedeflemesi Politikası", Sosyoekonomi, 29(49), 389-407.

Grafik 1'den de görülebileceği üzere belirtilen dönemde TÜFE oranlarında ciddi dalgalanmalar meydana gelmiştir. Dalgalanmanın her iki yönde şiddetli olması analiz döneminde fiyat istikrarının sağlanamadığını göstermektedir. $\mathrm{Bu}$ durum enflasyon hedeflemesi politikasının küresel finansal kriz sonrası dönemde başarılı olamadığını göstermektedir.

Literatürde yer alan hedefleme politikasının gelişmekte olan ülkeler için kriz ortamlarında uygun bir politika olmadığı tespiti Türkiye'nin gösterdiği performansla da doğrulanmıştır. Tam hedeflemenin ilk iki yılında grafikten de görülebileceği üzere hedefler aşılmıştır. 2008 yılında başlayan küresel finansal kriz ile hedeflerde değişikliklere gidilmiş gerçekleşmeler de uluslararası gelişmeler çerçevesinde hedefin altında kalmıştır. Küresel finansal kriz hem gelişmiş hem de gelişmekte olan ülkeleri etkilemiştir. Bu etkileri tespit edebilmek amaciyla enflasyon hedeflemesi politikası uygulayan ülkelerde yapısal kırılma testleri yapılmıştır. Bu testler sonucunda elde edilen kırılma tarihleri politika dinamiklerinde meydana gelen önemli değişikliklerin başlangıç tarihlerini vermektedir. Doğru (2012) Türkiye'deki enflasyon hedeflemesini inceleyen çalışmasında yer alan Chow Yapısal Kırılma Testi sonucunda 1994 ve 2001 yıllarında bir yapısal kırılma tespit edilmiştir. Ermişoğlu (2013) çalışmasında enflasyon hedeflemesi öncesi ve sonrası dönemlerin performansları değerlendirilmiştir. Söz konusu dönemlerde olması muhtemel kırılmaların tespiti amacıyla Quandt-Andrews Yapısal Kırılma Testi yapılmış testin sonucunda 2002 ve 2006 yıllarında kırılma tespit edilmiştir. Kutlar ve Gündoğan (2013) çalışmasında enflasyon hedeflemesi politikası uygulayan ülkelerde yapısal kırılma testi gerçekleştirilmiştir. Türkiye için Kasım 2008 tarihinde bir yapısal kırılmanın olduğu tespit edilmiştir. Söz konusu çalışmada politikayı uygulayan ülkelerin hemen tamamında kırılma tarihleri farklı çıkmıştır. $\mathrm{Bu}$ durum ülkelerin enflasyon hedeflemesini etkileyen etmenlere farklı zamanlarda tepki verdiğini göstermektedir. Kllıçkan (2014) Türkiye'de enflasyon hedeflemesinin makroekonomik etkinliği konusunda yaptığı çalışmasında Chow Yapısal Kırılma Testi’nde, TÜFE'de 2002 yılında bir kırılma tespit edilmiştir. Özkurt (2016) çalışmasında yapılan yapısal kırılma testi de Türkiye'de Kasım 2008 tarihinde bir kırılmanın varlığına işaret etmiştir. Literatürde yer alan bu çalışmalar çeşitli tarihlerde enflasyon hedeflemesi politikasında kırılmalar yaşandığını göstermektedir.

Hedefleme politikasında bir kırılma yaratan 2008 yılında politikada öngörülemeyen gerçekleşmeler meydana gelmiştir. 2007 yılında hizmet sektörünün TÜFE üzerindeki olumlu etkisine rağmen para politikasının etki alanı dişındaki petrol, gıda ve fiyatı yönetilen/yönlendirilen mal fiyatlarında yaşanan artışlar 2008 yılında TÜFE'nin hedefin üstünde \%10,1 oranında gerçekleşmesine neden olmuştur. 2008 yılında başlayan küresel finansal kriz nedeniyle ise iç talebin daralması ve buna bağlı olarak iktisadi faaliyetlerin yavaşlaması, talep daralmasına bağlı olarak petrol ve emtia fiyatlarında yaşanan düşüşün üretim maliyetlerine olumlu etkisi, Amerika Birleşik Devletleri (ABD) tarafından krizin olumsuz etkilerini ortadan kaldırmak amacıyla uygulanan miktarsal genişleme politikası sonucu piyasalarda bol ve ucuz doların olması gibi sebeplerden ötürü TÜFE oranlarında ileriki yıllarda düşüşler meydana gelmiştir. Krizin enflasyon oranlarında yarattığı azalma 
yönündeki baskı sayesinde 2009 ve 2010 yılında TÜFE oranları hedefin altında gerçekleşmiştir.

Türkiye Cumhuriyet Merkez Bankası, enflasyon hedeflemesi politikasının bir gereği olarak üç ayda bir enflasyon raporları açıklamaktadır. Bu raporlarda çeyreklik bazda temel makroekonomik durum hem dünya hem de ülkemiz açısından değerlendirilmektedir. Aynı zamanda bu raporlar enflasyon gerçekleşmeleri ve beklentileri hakkında da fikir vermektedir. Enflasyon raporlarından elde edilen bilgiler ışığında ülkemizde 2006 yılından itibaren enflasyon hedefinde meydana gelen sapmaların başlıca sebepleri şunlardır (TCMB, Enflasyon Raporlar1: 2006-2020);

- İşlenmiş ve işlenmemiş gıda fiyatlarındaki artış,

- Enerji fiyatlarındaki artış,

- Döviz kurunda meydana gelen artışlar,

- Vergi (özelikle özel tüketim vergisi) ayarlamaları,

- Geçmiş dönemdeki olumsuz gelişmelerinin gelecek dönem beklentilerinde yarattığı tahribat,

- Siyasi riskler,

- Jeopolitik konumdan kaynaklanan riskler,

- Uluslararası piyasalarda meydana gelen gelişmeler.

Tüketici fiyatlarının ölçülmesinde işlenmiş ve işlenmemiş gıda fiyatları önemli bir yer tutmaktadır. Dolayısıyla bu grupta meydana gelen artışlar TÜFE oranlarını doğrudan etkilemektedir. İşlenmemiş gıda ürünleri fiyatlarında meydana gelen her iki yönlü şiddetli dalgalanmalar TÜFE oranlarının hedeften sapmasının en önemli sebebi olmuştur. Gıda fiyatları para politikası yöneticilerinin etki alanı dışındadır. Bu yüzden bu grupta meydana gelen fiyat dalgalanmalarını ülke merkez bankaları uygulayacakları politikalarla etkileyememektedir. Ağırlığının fazla olmasına rağmen müdahale imkânı dışında olması bu gruptaki gelişmelerin önemini daha da artırmaktadır. İşlenmemiş gıda tanımı içerisinde taze sebze meyve, et ve süt fiyatları yer almaktadır. Tarımsal ürün üretimi büyük ölçüde hava koşullarına bağımlıdır. Mevsimin kurak geçmesi, olumsuz hava koşulları ve son yıllarda etkisini gittikçe artıran küresel 1sınma tarımsal üretim miktarını olumsuz yönde etkilemektedir. Tarımsal ürün fiyatları aynı zamanda kamuoyu tarafından da yakından takip edilmektedir. Bu grupta meydana gelen fiyat artışları kamuoyu tarafindan doğrudan enflasyon artışı şeklinde algılanmakta bu durumda da hedefleme politikasının başarısı konusunda olumsuz algı oluşmaktadır. Yine bu gruptaki aşırı fiyat artışları geleceğe yönelik beklentilerin de bozulmasına neden olmaktadır. İşlenmemiş gıda tanımı içerisinde yer alan kırmızı et fiyatlarında meydana gelen dalgalanmalar da fiyat artışlarını önemlide derecede etkilemiştir. Bu sorunun çözümüne yönelik olarak 2010 yılında kırmızı et ithalatına yönelik düzenlemeler yapılmıştır.

İşlenmiş gıdalar; belli bir işlem ve katma değer zincirinden geçtikten sonra hane halkının tüketimine arz edilen ürünlerdir. Bu ürünlere örnek olarak; meyve suları, işlenerek 
salam, sucuk vb. haline getirilmiş et ürünleri ve hammaddesi süt olan ürünler verilebilir (Başkaya, Gürgür \& Ögünç, 2008: 3). Dolayısıyla da işlenmiş ürünlerin hammaddesi olan et ve süt gibi ürünlerde yaşanan fiyat artışları doğrudan işlenmemiş ürün fiyatlarını artırırken dolaylı olarak da işlenmiş ürün fiyatlarını artırmaktadır. Ülkemizde son yıllarda özellikle kırmızı et üretiminde yaşanan sorunlar nedeniyle işlenmiş ürün fiyatlarında artışlar yaşanmıştır. İşlenmiş gıda fiyatlarında 2018 yılının üçüncü çeyreğinde döviz kurunda yaşanan aşırı artışların birikimli etkisi, et ve süt gibi işlenmiş gıda ürünlerinin hammaddesi konumundaki malların fiyatlarında yaşanan artışlar, geçmişe yönelik fiyatlama davranışları ve enflasyonun geleceği konusundaki olumsuz beklentiler sebebiyle önemli bir artış meydana gelmiştir (TCMB, 2018: 30).

Enerji tanımının içerisine başta ham petrol olmak üzere petrol türevleri, kömür ve endüstriyel madenler (metaller) yer almaktadır. Son yıllarda rüzgâr, hidro (su) ve güneş enerjisi de önemli birer enerji kaynağı haline gelmiştir. Türkiye bu enerji kaynaklarının en önemlisi olan petrol konusunda tamamen dışa bağımlıdır. Tamamen dışa bağımlı olduğumuz ham petrol fiyatlarında Amerikan Doları bazında yaşanan artışlar ve kurda meydana gelen dalgalanmalar enflasyonu olumsuz etkilemektedir. 2008 yılının üçüncü çeyreğinden itibaren uluslararası talepte meydana gelen azalmalara bağlı olarak enerji fiyatlarında düşüş meydana gelmiş bu da izleyen yıllarda TÜFE'nin hedefin altında kalmasını sağlamıştır. Enerji fiyatlarında meydana gelen artışlar talebin az olması durumunda hemen fiyatlara yansıtılmamaktadır. Bu durum birikimli etkinin doğmasına neden olmakta ve ileriki dönemlerde oluşan enflasyon artışlarına zemin hazırlamaktadır. Hedefleme dönemi boyunca ham petrol fiyatlarında yaşanan gelişmeler, önemli birer petrol üretici olan Venezuela, Libya ve İran gibi ülkelerde yaşanan iç karışıklıklar, ABD kaya petrolü üretiminin hız kesmesi, petrol üreticisi ülkelere konulan uluslararası ambargolar ve döviz kurunda yaşanan artışlar enerji fiyatlarının politika başarısızlığında önemli bir rol oynamasına neden olmuştur.

Türkiye'de enflasyon hedeflemesi politikasını olumsuz etkileyen bir diğer faktör döviz kurundaki oynaklıklardır. Nominal efektif döviz kuru bir ülkenin ağırlıklı olarak dış ticaret yaptığı ülkelerin para birimlerinden oluşan bir döviz sepetinin ağırlıklı ortalamasıdır. Reel efektif döviz kuru ise nominal efektif döviz kurundan nispi fiyat etkilerinin arındırılması yoluyla elde edilir. Özellikle son yıllarda Türkiye'nin ABD yönetimiyle yaşadığı gerginlikler, jeopolitik risklerin artması, geleceğe yönelik beklentilerde yaşanan olumsuzluklar gibi sebeplerden dolayı kurda istikrarsızlık daha da artmıştır. TCMB yönetiminin kuru baskı altına almak amacıyla döviz satım yoluna başvurması TCMB rezervlerinde aşırı azalma meydana getirmiş bu durum ileriye yönelik risklerin ve olumsuz algılamaların daha da artmasına neden olmuştur.

\section{GDP Hedeflemesi Politikası Uygulaması}

Türkiye'de açık enflasyon hedeflemesi döneminde politika hedeflerine ulaşamadığı Grafik 1'de açıkça görülmektedir. Hedefleme politikasında özellikle 2016-2020 döneminde ciddi başarısızlık hemen göze çarpmaktadır. Başarısızlığın nedenlerinin tespitinden sonra para politikası yöneticilerinin düşünmesi gereken konu bundan sonra nasıl bir yol 
Özkurt, İ.C. (2021), “Türkiye'de Enflasyon Hedeflemesi Politikasının

Başarısı ve GDP Hedeflemesi Politikası”, Sosyoekonomi, 29(49), 389-407.

izlenebileceği olmalıdır. Enflasyon hedeflemesi politikasının başarısı için politikanın güvenilirliği ve kamuoyunun gözünde kredibilitesi büyük önem arz etmektedir. Ancak yaşanan gelişmelerden sonra politikaya olan güvenden bahsedebilmek mümkün değildir. Artan fiyatlar nedeniyle geçim sıkıntısı içinde olan vatandaşlara enflasyonu düşürmeye yönelik bir politika uygulandığı ve bu politikayla enflasyonun düşürüleceğine inandırmak artık oldukça zordur. Hedeflerin revize edilmesi şeklinde yapılacak bir düzenleme ekonomik çevrelerin gözünde zaten güven kaybetmiş olan bu politikaya olan güvenin daha da sarsılmasına neden olacaktır. Türkiye gibi gelişmekte olan ülkeler para politikasına olan güven konusunda eksiktirler ve güveni sağlamak gelişmiş ülkelere göre hem daha önemli hem de daha zordur. Para politikasının uygulanmasında rol oynayacak kurumsal altyapının ya yeni kurulmuş ya da henüz kurulmamış olması, özellikle yakın geçmişte merkez bankasının kamuyu finanse bir kuruluş şeklinde çalışması ve yüksek kronik enflasyona sahip olmaları gelişmekte olan ülkelerin para politikası uygulamasının seçiminde ayırıcı özellikler olmaktadır. Hedeflenen enflasyon oranlarında katılıkların olması durumunda hedeflerin tutturulamaması inandırıcılığı ve kredibiliteyi oldukça olumsuz etkilemektedir.

Enflasyonun düşürülmesi konusunda enflasyon hedeflemesi politikasından önce uygulanan politikalardan birisi parasal hedefleme politikasıdır. Parasal büyüklüklerin hedeflenmesi politika yapıcıların uzun vadeli enflasyon hedeflerine ulaşabilmesinde yardımcı olması amacıyla seçilen bir para politikasıdır. Parasal hedefleme politikasında miktar teorisinin MV=PY denklemi kullanılmaktadır. Denklemde M para arzını, V dolanım hızını ve PY'de nominal geliri temsil etmektedir. V de meydana gelebilecek herhangi bir dalgalanma para talebindeki ters yönlü bir değişikliği temsil etmektedir. Para arzı ve para talebi arasındaki dengeyi sağlayabilmek için merkez bankası M'yi MV'yi sabit tutacak şekilde ayarlamak isteyecektir. Gerçek ekonomik hayatta ise merkez bankasının V'deki değişiklikleri tahmin ederek M'yi ayarlaması zordur (Hendrickson, 2020: 2). 1980'li yıllarda çoğu merkez bankası, enflasyonu kademeli olarak düşürme çabalarına rehberlik etmek için parasal büyüme hedeflerini kademeli olarak düşürmüştür. Para arzının hedeflemesine yönelik uygulamalarda para talebinin istikrarsızlığı nedeniyle parasal büyüklükler güvenilmez göstergeler haline gelmiştir. Birçok analist yanlış sinyallerin var olmasının doğru politikaların tespitinde başka göstergelerin kullanılmasına ihtiyaç duyulmasına neden olduğunu savunmuştur. Parasal hedefleme politikasından sonra uygulanan para politikası ise döviz kuru hedeflemesidir. Döviz kurunun hedeflenmesine dayanan bu politika da 1990'l1 yıllarda yaşanan kur krizleri sırasındaki spekülatif saldırılar sonucunda başarısız olmuştur.

Başlangıçta Meade (1978) ve Tobin (1980) tarafindan önerilen ve 1980'lerde diğer birçok iktisatçı tarafından desteklenen nominal GDP hedeflemesi politikasında amaç, güvenilir parasal genişleme ve artıştan ziyade, özellikle enflasyon oranında bir düşüş olmak üzere, güvenilir bir parasal disiplinine ulaşmaktır. Nominal GDP hedeflemesinin çekici özelliği, parasal ayarlamaların hedefleri belirlenirken daha kolay, daha sıkı ve daha değişmemiş bir parasal ortamda gelecekteki bilinmeyen şoklara karşı dayanıklı olmasıdır (Frankel, 2014: 1). Nominal GDP hedeflenmesi uygulamasının tercih edilmesinin nedenleri arasında basit ve kamuya açıklanan bir hedefe sahip olması nedeniyle sahip olduğu şeffaflık sayesinde beklentilerin sabitlenebilmesi de sayılabilir. 
Hall \& Mankiw (1993), nominal gelir hedeflemesinin birincil faydasının fiyat seviyesindeki ve enflasyon oranındaki dalgalanmayı azaltması olduğunu belirtmektedir. Paranın tam tarafsızlığı varsayımı altında nominal GDP'nin düzgün büyümesi fiyat seviyesinin de düzgün yolda ilerlemesini sağlayacaktır.

Para otoritelerinin nominal GDP hedeflemesi politikasını tercih etmesi konusunda Svensson (1998)'e göre; para otoritelerinin sadece nominal GDP büyümesini kontrol edebildiği buna karşın nominal GDP büyümesinin enflasyon ve reel GDP büyümesinden ayrışmadığı yönünde bir iddia öne sürmüştür. Bu durumda para otoritesi enflasyonu ve/veya çıktıyı ayrı ayrı kontrol etmek yerine nominal GDP büyüme oranına ulaşması daha güvenilir olacaktır.

Ball (1999) çalışmasında küçük kapalı bir ekonomide Taylor Kuralı olarak adlandırılan etkin bir kural politikasında nominal GDP hedeflemesinin hem enflasyonda hem de çıktıda büyük dalgalanmalara yol açacağından etkisiz olduğunu ileri sürmüştür.

Dennis (2001), çalışmasında Ball (1999) çalışmasında yer alan nominal GDP politikasının etkinsizliği görüşünü enflasyon beklentilerini de analize dahil ederek genişletmiştir. Enflasyon beklentileri dahil edildiğinde nominal GDP'nin istikrarsızlık yaratma ihtimalinin düştüğünü tespit etmiştir. Enflasyon beklentileri geriye ve ileriye yönelik bir karışım şeklinde ele alındığında nominal GDP büyümesinin bir istikrarsızlık yaratmadığı tespit edilmiştir.

Rudebusch (2002), nominal GDP hedeflemesinin hem fiyatlardaki hem de reel çıktıdaki hareketleri otomatik olarak hesaba kattığını ve para politikası için uzun vadeli bir nominal çapa görevi görebileceğini kabul etmektedir.

Henderson \& Kim (2005)'e göre optimal olmayan kurallar arasında nominal GDP hedeflemesi, makul parametre değerlerinde enflasyon hedeflemesine hakimdir. Her iki politika talep şoklarına yanıt vermede eşit derecede etkilidir. Bununla birlikte nominal GDP hedeflemesi, makul parametre değerlerinde verimlilik şoklarına yanıt vermede daha iyidir. Enflasyon önceden belirlenmiş olduğundan politika yapıcılar hedeflenen enflasyonla hiçbir şoka cevap vermez. Politika yapıcının yalnızca enflasyon ve çıktı hakkındaki bilgilerle yapabileceği en iyi şey katı nominal gelirli büyümeyi hedeflemesidir.

Sumner (2012)'a göre, 2008-2009 arasındaki olumsuz talep şoku, Amerika Birleşik Devletleri ve Avrupa'da ciddi bir resesyona yol açmıştır. Sumner para politikası yöneticilerinin resesyondan kurtulabilmek için nominal GDP'deki beklenen büyümeyi merkez bankasının büyüme hedefi olacak şekilde ayarlamaları gerektiğini savunmuştur. Böyle bir durumda bu hedef nominal bir GDP tahmin piyasası oluşturacak ve ardından nominal GDP vadeli işlem fiyatlarını stabilize etmek için para tabanını ayarlayabilecektir. Bu tür bir politika rejimi altında para tabanı ve kısa vadeli faiz oranlarının seviyesini merkez bankası değil piyasa belirleyecektir. Böyle bir rejimdeki mütevazı ayarlamalar, gelecek hedeflerine yönelik önceki birçok eleştiriye cevap verebilir. Çalışmada nominal GDP 
hedeflemesinin bazı yan faydalarına da yer verilmiştir. Bunlardan birisi beklenen mali çarpanın her zaman sıfır olacağıdır. Böyle bir durumda maliye politikasındaki değişiklikler nominal harcamalar üzerinde bir etkide bulunmayacaktır.

Hassan \& Loewald (2013)'e göre enflasyon hedeflemesi politikası numerik bir enflasyon hedefi esasına dayanırken, nominal GDP büyümesine odaklanmak hem enflasyonu hem de reel çıktıları göz önünde bulundurmanın basit ve temiz bir yoludur. Ayrıca merkez bankasının ortalama olarak kontrol edebileceği nominal bir hedefe odaklanması politikanın çekici ve pratik bir özelliğidir.

Frankel (2014), nominal GDP hedeflemesinin büyük gelişmiş ekonomilerin aksine orta büyüklükteki orta gelirli ülkeler için daha uygun olabileceğini öne sürmektedir. Bunun nedeni, bu tür ülkelerin sık sık arz şokları ve ticaret hadleri şokları ile karşı karşıya kalması bunun da enflasyon hedeflerinin veya döviz kuru hedeflerinin terk edilmesini zorunlu kılmasıdır. Ancak olumsuz arz şokunu otomatik olarak enflasyon ve reel GDP üzerindeki etkiler arasında eşit olarak bölen nominal bir GDP hedefinin terk edilmesi gerekli değildir.

Garin, Lester \& Sims (2016), fiyat ve ücret katılıklarıyla Yeni Keynesyen bir modelde nominal GDP hedeflemesinin arzu edilebilirliğini değerlendirmiştir. Nominal GDP hedeflemesi aynı zamanda hem nominal hem de reel değişkenleri hedefler. Hedeflenen nominal GDP'nin enflasyon hedeflemesinden önemli ölçüde daha iyi performans gösterdiğini ve ekonomi arz yönlü şoklara maruz kaldığında ve ücretler fiyatlara göre yapışkan olduğunda Taylor Kuralı'ndan daha küçük bir refah kayıplarıyla ilişkilendirildiğini tespit etmişlerdir. Bununla birlikte çıktı açığı hedeflemesi, en azından zayıf bir şekilde, nominal GDP hedeflemesini gerçekleştirme eğilimindedir ancak iki kuralla ilişkili refah kayıplarındaki farklılıklar küçüktür ve nominal GDP hedeflemesinin tercih edildiği durumlar vardir.

Beckworth \& Hendrickson (2020) standart bir Yeni Keynesyen modeli değiştirerek merkez bankasının çıktı açığı hakkında eksik bilgiye sahip olduğunu varsaymaktadır. Simülasyonları, nominal bir GDP hedefleme kuralının eksik bilgi altında Taylor Kuralı'na kıyasla hem enflasyonda hem de çıktı açığında daha düşük oynaklık ürettiğini göstermektedir.

Para politikasının uygulanması aşamasında politika yöneticilerinin önünde iki seçenek vardır. Bunlardan birincisi kurala dayalı bir politika izlemek diğeri ise takdire dayalı bir politika izlemektir. Kurala dayalı ve takdir yetkisine dayalı para politikası bir kuralın sistematik para politikası eylemini dikte etmesi ancak takdir yetkisi olmaması açısından temelde farklılık gösterir. Kurala dayalı bir politikada GDP gibi bir değişkenin hedeften sapması durumunda politika yöneticilerinin politikada ne zaman ve ne kadar ayarlamalar yapabileceğini önceden belirlenmektedir. Böylece politika uygulanmasındaki bütün eylemler bir sistematiğe bağlanmış olmaktadır. Takdire dayalı politikalarda ise politika yapıcılara politikada duruma göre ayarlama yapma imkânı tanımaktadır. Takdire bağlı politikanın izin verdiği sistematik olmayan politika ayarlamaları hedef oranı aşan ortalama 
bir nominal GDP büyüme oranıyla sonuçlanabilir. Sonuç olarak, takdire bağlı politika istenenden daha yüksek enflasyona neden olabilir. Takdire bağlı politika, politika yapıcılara zaman zaman açıklanan hedeflerden uzaklaşma seçeneği sunduğu için enflasyonist bir önyargıya maruz kalabilir. Örneğin, politika yapıcılar toplam arz şoku büyümeyi düşürdüğünde veya bir resesyona neden olduğunda nominal GDP büyümesini hedefin üzerine çıkarmaya karar verebilir. İsteğe bağlı bu tür geçişler yalnızca nominal GDP büyümesini hedefin üzerine itmekle kalmaz devam ettirildiği taktirde daha yüksek enflasyonla sonuçlanabilir.

Nominal GDP hedeflemesi parasal tabanın araç olarak kullanıldığg McCallum Kuralı'na dayanmaktadır. McCallum Kuralı Parasal Taban / GDP hedeflemesine dayanır. GDP büyümesinde sağlanacak bir istikrar beraberinde enflasyon oranında istikrarı da getirecektir. McCallum Kuralı basit şekilde (Mangır \& Ertem, 2016: 180);

$$
\begin{aligned}
& \Delta \mathrm{Bt}=\Delta \mathrm{Xt}^{*}-\Delta \mathrm{VBt}+\lambda\left(\mathrm{Xt}-1^{*}-\Delta \mathrm{Xt}-1\right) \\
& \mathrm{Bt}=\text { Para Tabanı (Rezerv }+ \text { Nakit }), \\
& \mathrm{VB}=\text { Son dört yılın para dolaşım hızı ortalama büyüme oranı, } \\
& \lambda=\text { Para tepki faktörü, } \\
& \mathrm{X}=\text { Nominal GDP } \\
& \mathrm{X}^{*}=\text { Hedef büyüme oranı (enflasyon ile reel GDP ortalama uzun dönemi toplamı) }
\end{aligned}
$$

ifade etmektedir.

Para arzında meydana gelen değişmeler, beklenen enflasyon, potansiyel ve reel GDP toplamına eşit olacaktır. Paranın dolaşım hızı para talebinde oluşacak geçici şoklara cevap verecektir ve uzun dönemde durağan kabul edilmektedir. $\mathrm{Bu}$ sayede nominal GDP beklenene eşit olacak ve kural enflasyonun uzun dönemde para politikasının nötr olmasından dolayı hedeflenen değerde kalmasını zorunlu kılacaktır. Formülde yer alan son değerler nominal GPD'de hedeften bir sapma söz konusu olduğunda para tabanının para politikası yöneticileri tarafından uyumlaştırmasını ifade ettiğinden önemli değerlerdir. Hedeflenenin altında bir gerçekleşme meydana geldiğinde para tabanı artırılacaktır (Mangır \& Ertem, 2016: 180).

Merkez bankası, nominal GDP'yi hedefleyerek esasen enflasyonu ve ekonominin uzun vadeli ortalama çıktı büyümesini (gerçek GDP) hedeflemektedir. Nominal GDP'nin izlenmesi merkez bankasina toplam nominal harcama sinyallerini vermekte ve merkez bankasının politika oranlarını ayarlanmasıyla toplam talep üzerindeki etkisi yoluyla harcamaları etkilemektedir (McCallum, 2011: 1).

Nominal GDP hedefleme kuralında büyüme oranları şu şekilde yazılabilir:

$$
\pi \mathrm{t}+\operatorname{InYt}-\operatorname{In} \mathrm{Y}_{\mathrm{t}-1}=0
$$


Bu kuralda, nominal faiz oranı, nominal GDP'nin büyüme oranının her dönemde sıfıra eşit olacak şekilde ayarlanır. Bu kuralın anlamı, enflasyon ve çıktı büyümesinin olumsuz olarak mükemmel bir şekilde ilişkili olacağıdır. $\mathrm{Bu}$ formülasyona dikkat edildiğinde nominal bir GDP büyüme oranı hedefi, tüm gelecek dönemlerdeki nominal GDP hedef seviyesinin t-1 dönemindeki nominal GDP seviyesi hedefine eşdeğerdir. Uzun vadede GDP seviyesi para politikası kuralından bağımsız olduğundan, uzun vadede nominal GDP hedefleme kuralı, uzun vadeli fiyat seviyesi hedefine eşdeğer olabilmektedir. (Garin vd., 2016: 25-6).

Literatür üç tip nominal GDP hedeflemesi politikası önermektedir (Hall \& Mankiw, 1993: 77);

- Büyüme oranı hedeflemesi; nominal gelir artışını mümkün olduğunca sabit tutma.

- Düzey hedefleme; politika ilk etkilerini göstermeye başladığı anda nominal gelir düzeyinin kural olarak belirlenen düzeye mümkün olduğunca yakın olmasını sağlamak.

- Hibrit hedefleme; reel gelir ile denge düzeyi arasındaki yüzde farkı sabitleyip gelecek yılın nominal gelir büyümesine ekleyerek mümkün olduğunda devam ettirmek.

Nominal GDP hedeflemesi uygulamasında hedef oran belirlenirken büyüme oranı ya da düzey seviyesinin hedeflenmesi konusu önemlidir. Merkez bankasının \%4,5'lik bir GDP büyümesi hedefi karşısında \%5,5'lik bir büyümenin gerçekleşmesi durumunda merkez bankasının önünde cevap vermesi gereken iki önemli soru vardır. Bunlardan birincisi, \%4,5'lik hedefi tutturmaya yönelik çaba sarf etmeli midir? İkinci soru ise daha önceden hedef olarak açıklanan \%4,5 oranına ulaşabilmek için yılsonundaki hedef \%4'e indirmeli midir? Bir başka deyişle nominal GDP hedefleri büyüme oranına göre mi yoksa büyüme düzeyine göre mi belirlenmelidir. Büyüme düzeyi temel alarak nominal GDP büyüme oranı hedefi belirlendiğinde hedef değerin altındaki gerçekleşmelerde nominal büyümeyi azaltmaya yönelik aşırı kısıtlayıcı politika uygulanmış olunması şeklinde bir dezavantaj mevcuttur. Böyle bir durumda birkaç dönem sonra kümülatif olarak amaçlanan yoldan daha da uzaklaşılması ihtimali artacaktır. McCallum daha önceden yaptığı çalışmalar 1şı̆̆ında hedef büyüme oranlarına bağlı kalınması halinde zamanla ortalama değerlerin de buna eşit olacağını ve hedeflenen yoldan çok fazla ayrılınmayacağından bunun tercih edilmesi gerektiğini belirtmiştir. Zaman içinde doğru değere eşit olan büyüme oranlarını korumak, amaçlanan yoldan çok fazla sapmaya izin vermeyecektir ve bu yüzden tercih edilmelidir (McCallum, 2015: 77).

Nominal GDP hedeflemesinde hedefte meydana gelebilecek sapmalar durumunda politika yapıcılar kısa vadeli faiz oranları ile müdahale edebilmektedir. Politika yapıcıların nominal GDP üzerinde doğrudan bir etkisi olmasa bile açık piyasa işlemleri yoluyla kısa vadeli faiz oranlarını etkileyebilirler (Clark, 1994: 13). Politika yapıcıların GDP hedefinden sapma söz konusu olduğunda buna nasıl müdahale edeceğine yönelik iki kural bulunmaktadır. Bunlar gecikmeli düzenleme kuralı ve tahmin düzenleme kuralıdır. 
Özkurt, İ.C. (2021), “Türkiye'de Enflasyon Hedeflemesi Politikasının

Başarısı ve GDP Hedeflemesi Politikası", Sosyoekonomi, 29(49), 389-407.

Gecikmeli düzenleme kuralı uyarınca, politika yapıcılar nominal GDP büyümesinin hedeften sapmasını gözlemledikten sonra kısa vadeli faiz oranını ayarlarlar. Politika yapıcılar, son çeyrekte nominal GDP büyümesi hedeflenen büyüme oranını aşarsa kısa vadeli faiz oranını artıracaktır. Tersine, son çeyrekte nominal GDP büyümesi hedeflenen oranın altında olunca da politika yapıcılar kısa vadeli faiz oranını düşürecektir. Kural, son çeyreğin nominal GDP büyüme oranı (yıllıklandırılmış) hedeften yüzde bir puan saptığında, politika yapıcıların cari faiz oranını sistematik olarak yüzde $\mathrm{x}$ oranında ayarlamasını şart koşar. Politika yapıcıların kısa vadeli bir faiz oranını ayarladığı andan itibaren, nominal GDP'nin yanıt vermesi iki ya da üç çeyreklik bir zaman alabilir. Faiz oranındaki bir değişiklik gelecekteki harcama planlarını hızlı bir şekilde etkileyebilirken planlardaki herhangi bir değişikliğin fiili harcamayı etkilemesinden önce birkaç ay geçebilmektedir.

Tahmin ayarlama kuralı para politikasının etkilerindeki gecikmeleri hesaba katan alternatif bir kuraldır ve nominal GDP büyümesini hedeflenen orana daha iyi dengeleyebilir. $\mathrm{Bu}$ alternatif tahmin ayarlama kuralı uyarınca, politika yapıcılar mevcut para politikasındaki bir düzeltmenin muhtemelen nominal GDP'yi gelecekte iki ila üç çeyreğe kadar etkilemeyeceğini kabul ederek ileriye yönelik bir ayarlamada bulunmaktadırlar. Bu alternatif kural, gelecekteki nominal GDP büyümesi tahminlerini kullanarak nominal GDP'nin gelecekteki beklenen sapmalarını dengelemeye çalışmak için mevcut para politikasını ayarlamayı amaçlamaktadır. Tahmin ayarlama kuralı uyarınca politika yapıcılar, nominal GDP'de beklenen gelecekteki büyüme hedeflenen orana eşit olana kadar cari kısa vadeli faiz oranını ayarlayacaklardır. Mevcut faiz seviyesinde tahminler gelecek yıl nominal büyümenin hedeflenen oranı aşacağını gösteriyorsa politika yapıcılar kısa vadeli faiz oranını artıracaktır. Faiz oranındaki artışın nominal GDP'de gelecekteki büyümeyi yavaşlatması ve sonuç olarak tahmin edilen nominal GDP büyümesini azaltması beklenmektedir. Politika yapıcılar faiz oranını yüksek orana dayalı olarak nominal GDP'nin gelecekteki büyümesi için öngörülen oranın hedeflenen orana eşit olmasını sağlayacak kadar artıracaktır. Tersine tahminler gelecek yıl nominal GDP büyümesinin hedefin altında olacağını gösteriyorsa politika yapıcılar tahminleri hedefe yükseltecek kadar kısa vadeli faiz oranını düşürecekler. Tahmin ayarlama kuralının bu versiyonunda, politika yapıcılar öngörülen nominal GDP büyümesini hedefte tutmak için cari bir faiz oranını ayarlama konusunda gelecek yıl için kendi tahminlerine güveneceklerdir (Clark, 1994: 14).

Tahmin ayarlama kuralının nominal GDP büyümesini dengelemede gecikmeli ayarlama kuralından daha üstün olduğunu varsayılmaktadır. Tahmin ayarlama kuralı nominal GDP'nin gelecekteki tahmin edilen hedeften sapmalarını önlemek için cari dönemde politika ayarlaması yapmaktadır. Bunun aksine gecikmeli ayarlama kuralında para politikası ancak nominal GDP gerçekten hedeften saptığında ayarlanmaktır. Politikanın bu gecikmiş tepkisi ve politika değişikliklerinin gecikmeli etkileri göz önüne alındığında para politikasının nominal GDP'yi hedefe doğru geri çekmeyi başarması için birkaç çeyreklik bir süre geçmesi gerekebilir. Ancak uygulamada tahmin edicilerin nominal GDP'de gelecekteki hareketleri tahmin etme konusunda hatalar yapmaları da söz konusudur. Tahmin hataları büyük ve sıksa gecikmeli ayarlama kuralı nominal GDP'yi daha iyi dengeleyebilmektedir. Tahmin hatası nedeniyle tahmin ayarlama kuralı nominal GDP'nin hedeften sapmasına 
Özkurt, İ.C. (2021), “Türkiye'de Enflasyon Hedeflemesi Politikasının

Başarısı ve GDP Hedeflemesi Politikası”, Sosyoekonomi, 29(49), 389-407.

neden olabilecektir. Analistler tahmin hatalarının büyüklüğü konusunda anlaşamadıkları için hangi kuralın nominal GDP'yi daha iyi dengeleyeceği konusunda hemfikir değildirler. Nominal GDP hedeflemesi politikası uygulamasında politika yapıcıların uygulama kuralları konusunda deneyimlere sahip olmaması yani bu politika uygulamasının sadece teori düzeyinde kalması ve henüz hiçbir ülkede uygulanmamış olması kural uygulamasının performansına ilişkin soru işaretlerini doğurmaktadır. Nominal GDP hedeflemesi politikasının en önemli eksiği olan gerçek ekonomik hayatta uygulanmamış olması sorunu burada da karşımıza çıkmaktadır (Clark, 1994: 15).

Merkez bankasının enflasyonu düşürücü bir politika izlemesi bir ikilem oluşturabilmektedir. Fiyat seviyesinin dengelenmesine yönelik politikalar reel üretimde daha fazla düşüşe neden olabilmektedir. Nominal GDP hedeflemesi hem gerçek çıktı hem de fiyat seviyesinin istikrarına eşit vurgu yaptığı için politika yapıcılara bu ikilemi çözmelerinde yardımcı olabilmektedir. Nominal GDP politikası arz şoklarının olumsuz etkisini enflasyon ve gerçek GDP büyümesi arasında bölerken, enflasyon hedeflemesinde ise arz şokunun olumsuz etkisi tümüyle reel GDP büyümesine yansımaktadır (Malik, 2003: 5-6). Enflasyon hedeflemesi uygulayan özellikle gelişmekte olan ülkeler talep ve arz şoklarının olumsuz etkilerine daha açık ülkelerdir. Nominal GDP hedeflemesinde talepte meydana gelecek şoklar para politikasıyla ayarlanabilir. Örneğin, çıktının ve fiyatların hedefin altına düşmesine neden olan olumsuz bir talep şoku durumunda politika yapıcılar nominal geliri hedefe döndürebilmek amacıyla para politikasını kolaylaştırıcı yönde müdahalelerde bulunabilecektir. Ülkenin dış ticaret ortaklarında yaşanan durgunluk ülke ihracatını olumsuz etkileyecektir. Dış talepte meydana gelecek bu azalma nominal GDP ve buna bağlı olarak da reel GDP büyümesinin azalmasına neden olacaktır. Bu durumda nominal GDP büyümesini eski seviyesine yükseltebilmek amacıyla politika yapıcılar para politikasında gevşemeye gideceklerdir. Böylelikle talebi artırıcı bu önlemler sayesinde nominal ve reel GDP talep yetersizliği öncesi seviyesine geri dönecektir (Clark, 1994: 12).

Yurtiçinden ve yurtdışından gelebilecek ticaret şoklarına daha savunmasız olan gelişmekte olan ülkelerin üç kategoride arz veya ticaret şokuna maruz kalmaları söz konusudur (Bhandari \& Frankel, 2014, 4-5):

a. Saf arz şoku. Doğal afetler (deprem, kasırga, kasırga veya sel gibi), hava ile ilgili diğer olaylar (kuraklık veya şiddetli kış), sosyal bozulma (işçi grevi veya sosyal huzursuzluk) ve diğer üretkenlik şokları (teknolojik ilerleme) bu kategoriye girer. Enflasyon hedeflemesi politikasından para politikasının fiyat seviyesindeki herhangi bir artışı ortadan kaldıracak kadar sıkılaştırılması gerekmektedir. Bu durum yine daha düşük GDP büyümesine yol açar. Nominal GDP hedeflemesi politikasında ise para birimi olumsuz arz veya ticaret hadleri şokları kadar değer kaybederek ticaret dengesine yardımcı olacak ve şokun olumsuz etkisini enflasyon ile büyüme arasında bölerek yanıt verebilecektir.

b. Ithalat fiyatlarında artış. Ticaret hadleri şoklarının bir şekli, ithal edilen malların dünya fiyatlarındaki artıştır. Petrol fiyatları bu konuya güzel bir örnektir. Döviz kuru hedeflemesi olması durumunda, döviz kuru hedefleme politikasının tanımı gereği ticaret 
Özkurt, İ.C. (2021), “Türkiye'de Enflasyon Hedeflemesi Politikasının

Başarısı ve GDP Hedeflemesi Politikası", Sosyoekonomi, 29(49), 389-407.

dengesi ve GDP için olumsuz etkilerle birlikte para biriminin değer kaybetmesi önlenir. Enflasyon hedeflemesi durumunda para birimi, ticaret dengesi ve büyüme için daha da kötü etkilerle birlikte TÜFE enflasyonundaki artışı önlemek için gerçekten değer kazanmalıdır. Nominal GDP hedeflemesi durumunda aksine para biriminin değer kazanmasına neden olmaz. Yine olumsuz şok tek başına büyümeden ziyade enflasyon ve GDP büyümesi arasında bölünür.

c. İhracat fiyatında düşüş. Gelişmekte olan birçok ülke, dünya pazarlarında büyük fiyat dalgalanmaları yaşayan malları ihraç etmektedir. Döviz kurunun hedeflenmesi durumunda para birimi ayarlanamaz. Enflasyon hedeflemesi durumunda amortisman da enflasyonu artıracağından etkisi sınırlıdır. Böylece ticaret dengesi de GDP büyümesi gibi kötüleşir. Nominal GDP hedefinde para birimi değer kaybederek ticaret dengesinin yanı sıra GDP büyümesinin ekonomik daralmayı iyileştirmesine ve hafifletmesine yardımcı olur.

Nominal GDP hedeflemesi politika yapıcıların toplam arz şoklarına yanıt verirken istikrarlı büyüme ve enflasyon hedeflerini dengelemelerine yardımcı olmaktadır. Kısa vadede petrol fiyatlarında bir artış gibi olumsuz bir arz şoku iki istenmeyen sonuç doğurur; düşen reel GDP büyümesi ve yükselen enflasyon. Bu sonuçlar bir ikilem oluşturmaktadır. Para politikasının bir değişkeni istikrara kavuşturacak şekilde değiştirilmesi diğer değişkende ek oynaklık yaratır. Örneğin, petrol fiyatlarındaki artışla yavaşlayan bir ekonomiyi canlandırmak için politikayı gevşetmek reel GDP büyümesindeki düşüşü sınırlayacak ancak enflasyonu artıracaktır. Tersine enflasyonu dengelemeye yönelik sıkılaştırma politikası reel GDP'deki düşüşü şiddetlendirecektir. Nominal GDP hedeflemesi, politika yapıcıların hem reel GDP büyümesinin hem de enflasyonun istikrarına eşit vurgu yaparak ikilemi çözmelerine yardımcı olacaktır. Nominal GDP hedeflemesi, toplam arz şokunun çıktı ve enflasyon etkilerini eşitleyecek şekilde ayarlanacaktır. Örneğin, reel GDP büyümesinin yüzde 1 düşmesine ve enflasyonun yüzde 0,5 artmasına neden olan bir petrol fiyatı artışı nominal GDP büyümesini de yüzde 0,5 azaltacaktır. Nominal GDP hedeflemesi altında para politikası nominal GDP büyümesini yüzde 0,5 artıracak ve böylece nominal GDP büyümesini hedeflenen oranına döndürecek kadar canlandırarak yanıt verecektir. $\mathrm{Bu}$ politika tepkisinin bir sonucu olarak, reel GDP büyümesi düşecek ve enflasyon aynı miktarda, örneğin yüzde 0,75 artacaktır. Bu nedenle nominal GDP hedeflemesi arz şokunun sonuçlarını dengeleyecektir (Clark, 1994: 12-3).

Nominal GDP hedeflemesinde reel çıktıda meydana gelen her \%1'lik azalma karşısında fiyatlar genel düzeyindeki azalış bundan daha fazla olacaktır. Bu politikanın çekici özelliği ekonominin genel özelliklerine ve parasal tarafsılı̆̆ın sağlamlığından kaynaklanmaktadır. Politika oluşturulurken nominal GDP'nin formüle edilmesi aşamasında aşağı ve yukarı yönlü birkaç puanlık bir bant bırakılması gereklidir. Bunun sebebi; nominal gelirin öngörülemez belirleyicilerinin varlığıdır. Bırakılan bant boşluğu sayesinde kamuoyu, son zamanlarda meydana gelen gelişmelerin politika kuralından sapmaya yol açtığını ya da merkez bankasının kuraldan ayrılma kararının sonucu olup olmadığını bilemez. Aksine politika gelecekteki bir ya da iki yıllık tahmine dayanıyorsa herhangi bir banda gerek yoktur. Eğer tahminde bulunanlar nominal gelirin hedefin altında kalacağı konusunda görüş 
Özkurt, İ.C. (2021), “Türkiye'de Enflasyon Hedeflemesi Politikasının

Başarısı ve GDP Hedeflemesi Politikası”, Sosyoekonomi, 29(49), 389-407.

birliğine sahipse kamuoyu ve meclis merkez bankasının politikaya bağlı kalma konusunda başarısız olduğunu anlayacaktır (Hall \& Mankiw, 1993: 78).

Nominal GDP hedeflemesi politikasının bahsedilen bu avantajlarına karşın bir takım dezavantajları da mevcuttur. Nominal GDP para otoriteleri tarafından kolaylıkla kontrol edilebilen bir büyüklük değildir. Nominal GDP verileri zaman yönünden bir gecikme ile elde edilmekte ve serilerde hatalar görülebilmektedir. Bu yüzden serilerde zaman zaman revizeye gitmek gerekmektedir. Bunun sonucunda nominal GDP hedefine ulaşılmasının değerlendirilebilmesi için uzun bir zaman dönemi gerekmektedir. Yanı sıra reel çıktı trendini tahmin etmek de çok güçtür. Dolayısıyla hedeflemede istenmeyen gerçekleşmelerin meydana gelmesi durumunda bunun farkına varılıp değerlendirilmesi uzun bir süreç gerektireceğinden bu olumsuzlukları gidermeye yönelik uygulanacak politikalar ve bu politikalardan beklenen sonuçlar da uzun bir gecikme dönemi sonunda ortaya çıkacaktır. Sorunların fark edilip çözüme kavuşturması aşamasındaki bu zorluklar politikanın uygulanmasını zorlaştırmaktadır. Fiyatlarla ilgili veriler ise nominal gelir verilerine göre daha kolay ve kısa sürede elde edilir. Nominal gelirin ölçülmesi mevcut fiyatlarla ilgili bilgilere bağlı olduğu kadar mevcut büyüklüklerle ilgili verilere de bağlıdır. Bu yüzden ölçüm işlemlerinin zamanında gerçekleştirilmesi kolay değildir (Oktar, 1998: 58-9).

Nominal GDP hedeflemesi uygulayan bir hükümet ya da merkez bankası potansiyel GDP büyüme oranlarını piyasayla paylaşmak zorundadır. Bu şekilde sayısal bir değer biçiminde yapılan bir açıklama potansiyel GDP rakamlarının bir kesinlik taşımaması, zaman içinde değişiklikler gösterebilmesi ve çok sayıda değişkenin etkisinde olmasından dolayı ileride önemli sorunlar doğurabilecektir (Mishkin \& Posen, 1997: 7). Dolayısıyla, politikacıların emin olmadıkları halde, potansiyel nominal GDP artışı ile ilgili belirli bir sayısal rakam ilan etmeleri, halkın yanlış bir biçimde bu rakamın kesin ve sabit bir hedef olduğunu düşünmesine yol açabilir. Bu yönde bir açıklama piyasalar tarafından bir hedefmiş gibi algılanıp buna göre pozisyon almalarına yol açabilir. Aynı zamanda bir hedef büyüklüğün açıklanmasıyla politika yapıcılarla siyasiler arasında çekişmeler ortaya çıkabilir.

Nominal GDP hedef oranının belirlenmesi zordur. Hedefin yüksek olarak belirlenmesi durumunda enflasyonist baskılar da ortaya çıkabilir. Böylelikle fazla belirlenmiş bir GDP hedefi enflasyonist sonuçlar doğurabilir. Aksine ilan edilen hedef piyasalar tarafından çok düşük olarak algılanırsa bu sefer de hükümet büyüme karşıtı bir politika izlediği şeklinde eleştirilere maruz kalarak siyasi tartışmaların alevlenmesine neden olabilir (Devine \& McCoy, 1998: 5).

GDP hedeflemesi politikası halk tarafından daha kolay kabul edilebilir bir politika şeklinde sahip olduğu avantaja rağmen dezavantaj olarak GDP kavramının kamuoyu tarafından tam olarak anlaşılamaması durumu söz konusudur. Aynı zamanda nominal GDP reel GDP ayrımında bir sorun ortaya çıkıp merkez bankasının açıkladığı nominal GDP hedefi kamuoyu tarafından reel GDP hedefi şeklinde yanlış algılanabilir. Hedefin ne olduğu konusunda kamuoyunun kafasında bazı şüphelerin var olması özelikle enflasyon 
hedeflemesi politikasının önemli özelliklerinden birisi olan şeffaflık özelliğinin nominal GDP hedeflemesi politikasında sağlanamamasına yol açabilir.

Toplu iş sözleşmeleri pazarlıklarında özellikle işçi kesimi nominal GDP'deki değişiklikleri değil enflasyon oranındaki değişmeleri dikkate almaktadır. Dolayısıyla yeni ücret düzeylerinin belirlenmesi aşamasında hükümet, işveren ile işçi kesimi arasında görüş ayrılıkları ortaya çıkacaktır. İşçi kesimi GDP rakamları ve bu rakamlardaki değişmeler konusunda bilgisiz ve ilgisiz olduğundan hükümetin nominal GDP hedeflemesi konusundaki görüşlerini anlamayacak ve kabul etmeyecektir. Ücret düzeylerinin enflasyon oranına göre belirlenmesi durumunda ise nominal GDP hedeflemesi politikasının başarısı sekteye uğrayabilecektir.

Nominal çıktı hedeflemesine karşı en güçlü iddia, para politikası eylemlerine reel çıktı ve enflasyonun verdikleri yanıtların farklı oluşudur. Para politikası eylemlerine çıktı enflasyona göre daha çabuk yanıt verirken etkileri de oldukça farklıdır. Nominal çıktıya tepki veren bir politika kuralı, zorunlu olarak çıktı açıklarındaki artış ve enflasyondaki dalgalanmalara aynı şekilde yanıt verir ve bu nedenle senkronize olmamış parasal aktarım gecikmelerinde iyi sonuç vermez. Para politikasının enflasyonu daha kısa sürede etkilediği basit geriye dönük toplam talep-arz modelinde nominal çıktı hedeflemesi, çıktı ve enflasyon için sonsuz değişkenlik gösteren dinamik bir istikrasızlığa yol açmaktadır (Rudebusch, 2002: 403).

Nominal GDP hedeflemesinin en önemli eksikliği henüz hiçbir ülkede fiilen uygulanmamış olmasıdır. Her ne kadar teoride uygulanabilir bir politika olarak görünse de gerçek ekonomik hayatta uygulama aşamasında politikanın vereceği tepkilerin diğer makroekonomik değişkenlere yansımasının nasıl olacağı tahmin edilememektedir. Dolayısıyla nominal GDP hedeflemesi politikasının başarısı konusunda kesin fikirler öne sürmek bu aşamada mümkün değildir.

\section{Sonuç ve Değerlendirme}

Küresel finansal krizle birlikte tüm dünyada düşük-1lımlı enflasyon ve yüksekistikrarlı büyüme dönemi sona ermiştir. Bu durum aynı zamanda enflasyon hedeflemesi politikasına yönelik eleştirilerin de artmasına yol açmıştır. Özellikle gelişmekte olan ülkelerde uygulanan hedefleme politikası her ne kadar enflasyonu düşürmede başarılı olsa da küresel kriz ile birlikte diğer makroekonomik değişkenlerde meydana gelen bozulmalar enflasyon oranlarının düşürülmesi konusunda sağlanan başarının gölgede kalmasına neden olmuştur. Enflasyon hedeflemesi politikasının sadece fiyat istikrarına odaklanması ve diğer makroekonomik değişkenleri dikkate almaması konusu ekonomi çevrelerince şiddetle eleştirilmeye başlanmıştır.

Kriz ile birlikte ortaya çıkan deflasyonist etkilere karşı enflasyon hedeflemesi politikası etkisizdir. Hatta bazı iktisatçılar tarafından bizzat hedefleme politikasının deflasyonu yarattığı şeklinde eleştiriler ortaya atılmıştır. GDP hedeflemesi politikasının 
tekrar gündeme gelmesini sağlayan bu olumsuz durum ülkemizde de etkin bir şekilde hissedilmiştir.

Türkiye'de enflasyonu etkileyen çok sayıda içsel ve dişsal etmen söz konusudur. Dışsal etmenlerden birincisi ülkemizin içinde bulunduğu jeopolitik konumun yarattığ 1 risklerdir. Güney doğu komsularımız olan Suriye ve Irak’ta yaşanan iç savaş ve kargaşa ortamı doğrudan Türkiye ekonomisini etkilemektedir. Jeopolitik ve siyasi risklerin artması ülke risk priminin de artmasına ve dolayısıyla yabancı sermayenin (doğrudan ve dolaylı) gelmesini engellemektedir. Türkiye'nin sahip olduğu sermaye yetersizliği durumu nedeniyle yurtdışından gelen sermaye akımlarında yaşanan azalma ve hatta geri dönmeler doğrudan kurlar üzerinde artış baskısı yaratmaktadır. Kurlarda yaşanan aşırı artışlar üretim maliyetlerini etkileyerek fiyatlar genel seviyesini yükseltmektedir. $\mathrm{Bu}$ durum en yakın tarihte 2018 yılının ikinci yarısından itibaren görülmüştür. Kurlar siyasi risklerin artması neticesinde tarihinin en üst seviyesine yükselmiş bu durumda enflasyonun hedef seviyelerinin çok üstünde gerçekleşmesine neden olmuştur. Aynı zamanda siyasi riskler ortadan kalktıktan sonra kurların eski seviyesine geri dönmemesi (aşağı yönlü yapışkanlıklar) bu artışın kalıcı olmasına yol açmıştır.

Enflasyon hedeflemesi politikasında özellikle gelişmekte olan ülkelerde yaşanan sorunlar neticesinde GDP hedeflemesi politikası iktisadi tartışmalara yeniden konu olmuştur. Nominal GDP hedeflemesi politikası savunucuları, politikanın özellikle gelişmekte olan ülkelerin çok fazla karşılaştıkları arz ve talep şoklarına karşı daha dayanıklı olduğunu savunmaktadır. Şokların olumsuz etkilerinin otomatik olarak enflasyon ve reel GDP üzerine eşit olarak dağıtılması olumsuzluk durumunda enflasyon hedeflemesi politikasında başvurulduğu gibi hedeflerin terk edilmesi zorunluluğunu ortadan kaldırmaktadır. Çalışma boyunca elde edilen temel düşünce nominal GDP hedeflemesi politikasının özellikle olumsuz arz ve talep şokları durumunda daha etkin olduğudur. Bu yüzden Türkiye'nin özellikle son yıllarda içsel ve dişsal sebeplerden kaynaklanan bu tür şoklar karşısında enflasyon hedeflemesi politikası nedeniyle savunmasız olması ve olumsuz etkilerin ekonomiyi oldukça fazla etkilemesi nedeniyle nominal GDP hedeflemesi politikasının bu olumsuzluğu giderebilme konusunda yardımcı olabileceği düşünülmektedir.

GDP hedeflemesi politikasında da şeffaflık unsuru ön plana çıkmaktadır. Tıpkı enflasyon hedeflemesinde olduğu gibi hedefin kolay ve anlaşılır olması, kamuoyuna açıklanması ve gelişmelerin de paylaşılması şeffaflığın kaynağını oluşturmaktadır. Dolayısıyla nominal GDP hedeflemesi politikası uygulamasında kamuoyunun desteğini almak da kolay olmaktadır.

Nominal GDP'nin hedefler çerçevesinde düzgün büyümesi fiyat seviyesinin de düzgün büyümesini sağlamaktadır. Aynı zamanda GDP'nin uzun vadeli bir çapa olarak kullanılması enflasyonda meydana gelen dalgalanmaların boyutunu da azaltmaktadır.

Nominal GDP hedeflemesinin bir teori olarak kalması yani hiçbir ülkede bizzat uygulanmamış olması bu aşamada nominal GDP hedeflemesinin Türkiye'de enflasyon 
hedeflemesi politikasının yerini alıp alamayacağı konusunda soru işaretlerini de beraberinde getirmektedir. Kâğıt üzerinde kusursuz gibi görünen teorilerin uygulamada her zaman başarılı olamadığı açıktır. Dolayısıyla da nominal GDP hedeflemesinin enflasyon hedeflemesi politikasının yerini alacak, fiyat istikrarı ve finansal istikrarı yaratacak genel geçer bir politika olabileceği şu aşamada söylenememektedir.

\section{Kaynaklar}

Ball, L. (1999), "Efficient Rules for Monetary Policy”, International Finance, 2(1), 63-83.

Başkaya, Y.S \& T. Gürgür. \& F. Öğünç (2008), "Küresel Isınma, Küreselleşme ve Gıda KriziTürkiye'de İşlenmiş Gıda Fiyatları Üzerine Ampirik Bir Çalışma”, Türkiye Cumhuriyet Merkez Bankasi, Central Bank Review, 2, 1-32.

Beckworth, D. \& J.R. Hendrickson (2020), "Nominal GDP Targeting and the Taylor Rule on an Even Playing Field”, Journal of Money, Credit and Banking, 52(1), 269-286.

Bhandari, P. \& J. Frankel, (2014), "The Best of Rules and Discretion: A Case for Nominal GDP Targeting in India", Working Papers Center for International Development at Harward University, 284, 1-29.

Clark, T.E. (1994), "Nominal GDP Targeting Rules: Can They Stabilize the Economy?”, Federal Reserve Bank of Kansas City, Economic Review, 11-25.

Dennis, R. (2001), "Inflation Expectations and the Stability Proporties of Nominal GDP Targeting”, The Economic Journal, 111(468), 103-113.

Devine, M. \& D. McCoy (1998), The Formulation of Monetary Policy in EMU, Economic Analysis, Research and Publications Department, Central Bank of Ireland, 1-26.

Doğru, B. (2012), "Merkez Bankası Politikalarının Fiyat İstikrarı ve Diğer İktisadi Olgular Açısından Değerlendirilmesi ve Türkiye'de Enflasyon Hedeflemesi Örneği”, İstanbul Üniversitesi, Sosyal Bilimler Enstitüsü, İktisat Anabilim Dalı, Yayınlanmamış Doktora Tezi, İstanbul.

Ermişoğlu, E. (2013), “Türkiye'de Enflasyon Hedeflemesi: Bir Başarı Hikâyesi Mi?”, BDDK Bankacılık ve Finansal Piyasalar, 7(1), 31-58.

Frankel, J. (2014), "Nominal GDP Targeting for Middle-Income Countries", Harvard Kennedy School, Faculty Research Working Paper Series, 14-033, 1-13.

Garin, J. \& R. Lester \& E. Sims (2016), "On the Desirability of Nominal GDP Targeting”, NBER Working Paper Series, 21420, 21-44.

Hall, R.E. \& G.N. Mankiw (1993), "Nominal Income Targeting”, National Bureau of Economic Research, 4439, 71-94.

Hassan, S. \& C. Loewald (2013), "Nominal GDP Targeting and the Monetary Policy Framework", South African Reserve Bank Working Paper, WP/13/05, 1-17.

Henderson, D. \& J. Kim (2005), "Inflation Targeting and Nominal Income Growth Targeting: When and Why Are They Sub Optimal?, Journal of Monetary Economics, 52(8), 1463-1495.

Hendrickson, J.R. (2020), “Commodity Money, Free Banking and Nominal Income Targeting: Lessons for Monetary Policy Reform”, The Quarterly Review of Economics and Finance, G Model QUAECO-1407, 1-16.

Kara, H. \& M. Orak (2008), "Enflasyon Hedeflemesi”, Ekonomik Tartışmalar Konferansı, İstanbul. 
Kılıçkan, Z. (2014), "Fiyat İstikrarı ve Enflasyon Hedeflemesi Stratejisinin Makroekonomik Etkileri: Türkiye Örneği”, Kocaeli Üniversitesi, Sosyal Bilimler Enstitüsü, İktisat Anabilim Dalı, Yayınlanmamış Doktora Tezi, Kocaeli.

Kutlar, A. \& H. Gündoğan (2013), “Türkiye'de 2008 Finansal Kriz Sürecinde Para Politikas1 ve Enflasyon Hedeflemesi”, EKEV Akademi Dergisi, 17(54), 269-283.

Malik, H.A. (2003), "Price Level vs. Nominal Income Targeting and the Cost Channel of Monetary Policy Transmission", Lakehead University, Department of Economics, Ontario, Canada, $1-29$.

Mangır, F. \& C. Ertem (2016), “Alternatif Para Politikası Stratejisi Olarak Nominal GDP Hedeflemesi: Karşılaştırmalı Bir Analiz”, Sosyal Ekonomik Araştırmalar Dergisi, 16(31), 162-185.

McCallum, T.B. (2011), "Nominal GDP Targeting”, Shadow Open Market Committee, Economic Policies for the 21 st Century, 1-4.

McCallum, T.B. (2015), "Nominal GDP Targeting: Policy Rule or Discretionary Splurge?”, Journal of Financial Stability, 17, 76-80.

Mishkin, F.S \& A.S. Posen (1997), "Inflation Targeting; Lessons From Four Countries", NBER Working Paper Series, 6126, 1-33.

Oktar, S. (1998), Enflasyon Hedeflemesi, Para Politikasının Güvenilirliği ve Fiyat İstikrarı, Bilim Teknik Yayınevi, İstanbul.

Özkurt, İ.C. (2016), “Türkiye’de Enflasyon Hedeflemesi Politikasını Etkileyen Etmenler; Ekonometrik Bir Analiz”, Balıkesir Üniversitesi Sosyal Bilimler Enstitüsü Dergisi, 19(5), 431-453.

Rudebusch, G.D. (2002), “Assessing Nominal Income Rules for Monetary Policy with Model and Data Uncertanity", The Economic Journal, 112, 402-432.

Sumner, S. (2012), The Case for Nominal GDP Targeting, Mercatus Center at George Mason University.

Svensson, L.E.O. (1998), "Inflation Targeting: Some Extensions", NBER Working Paper Series, $5962,1-45$.

Türkiye Cumhuriyet Merkez Bankası (2018), Enflasyon Raporu.

Üzar, U. \& A. Başoğlu (2017), "Merkez Bankacılığı ve Yeni Arayışlar: Nominal GSYH Hedeflemesi ve Kalkınmacı Merkez Bankacılığı Tartışmaları", Karadeniz Teknik Üniversitesi Sosyal Bilimler Dergisi, 7(13), 123-145. 
Özkurt, İ.C. (2021), “Türkiye'de Enflasyon Hedeflemesi Politikasının Başarısı ve GDP Hedeflemesi Politikası”, Sosyoekonomi, 29(49), 389-407. 